\title{
Sectoral Systems and Innovation and Technology Policy
}

Franco Malerba

CESPRI - Bocconi University

\section{ABSTRACT}

This paper uses the concept of sectoral system of innovation which aims to provide a multidimensional, integrated and dynamic view of innovation in sectors. Sectoral systems have three dimensions that affect the generation and adoption of new technologies and the organization of innovation and production at the sectoral level: knowledge (and the related boundaries), actors and networks, and institutions. The paper discusses the conceptual framework of sectoral systems, presents five main sectoral systems and examines their major trends, challenges and transformation. The paper then examines which are the main policy implications and indications in a sectoral system perspective.

KEYWORDs | Technological Innovation; Innovation Systems: Sectors; Public Policy JEL-Codes | L0, O14, O3

\section{RESUMO}

Este artigo usa o conceito de sistema setorial de inovaçóes que permite a utilização de uma visão multidimensional integrada e dinâmica da inovação em seus setores. Sistemas setoriais apresentam três dimensões que afetam tanto a geração e adoção de novas tecnologias quanto a organização da inovação e produ- 
ção nos seguintes níveis setoriais: conhecimento, atores e redes e instituições. $\mathrm{O}$ artigo discute o escopo conceitual dos sistemas setoriais, apresenta cinco análises de setores principais e examina suas tendências principais, seus desafios e suas transformações. $\mathrm{O}$ artigo também oferece uma análise sobre implicações políticas públicas e sugestôes do ponto de vista do sistema setorial de inovaçôes.

PalaVRAS-Chave | Inovação Tecnológica Setorial; Sistemas de Inovações: Setores; Políticas Públicas

Códigos JEL | L0, O14, O3

\section{Introduction}

For an understanding of innovation and economic growth, sectors provide a very important level of analysis for economists, business scholars, technologists and economic historians. Until recently, sectors have often been examined according to the standard industrial economics literature (the structure-conductperformance tradition, the transaction costs approach, sunk cost models, game theoretic models of strategic interaction and cooperation, and econometric industry studies) in which sectoral boundaries have been considered static and well delimited and differences in the equilibrium structure of sectors have been considered as determined by the underlying patterns of technology and demand, in addition to the type of sunk costs (Bain, 1956; Scherer, 1990; Tirole, 1988; Sutton, 1991, 1998). In most of these studies, however, not much emphasis has been paid to the role of non-firms organizations, to knowledge and learning processes by firms, to the wide range of relations among the agents, to the transformation of sectors in their boundaries, actors, products and structure. A second tradition dealing with sectors is much richer empirically but much more heterogeneous, eclectic and dispersed. Here one finds very rich empirical evidence on the features and working of sectors, on their technologies, production features, innovation, demand and on the type and degree of change. But most of the sector case studies focus on a single dimension (such as innovation, firms' 
competences, structure of production and so on), ask different research questions, are done with different methodologies and have a different level of aggregation in terms of unit of analysis. As a consequence, the possibility of having integrated and consistent analyses of sectors in their interrelated dimensions and understanding fully their working and transformation is still very limited.

This paper uses the concept of sectoral system of innovation and production which aims to provide a multidimensional, integrated and dynamic view of sectors. Sectoral systems have a knowledge base, technologies, inputs and a (potential or existing) demand. The agents are individuals and organizations at various levels of aggregation, with specific learning processes, competences, organizational structure, beliefs, objectives and behaviors. They interact through processes of communication, exchange, cooperation, competition and command, and their interactions are shaped by institutions. A sectoral system undergoes processes of change and transformation through the coevolution of its various elements. The main advantages of a sectoral system view are a better understanding of the sectoral structure, boundaries and transformation and the agents and their interactions.

Sectoral systems have three broad dimensions that affect the generation and adoption of new technologies and the organization of innovation and production at the sectoral level:

a) knowledge (and the related boundaries)

b) actors and networks

c) institutions.

They will be discussed in the following pages.

This paper draws from the main results of the ESSY project ${ }^{1}$. ESSY has analysed six major sectoral systems in Europe.

\footnotetext{
1 Sectoral Systems in Europe - Innovation, Competitiveness and Growth (ESSY) [Project financed within the TSER Programme - Contract n. SOE 1-CT 98-1116].

I wish to thank the main participants to ESSY: R. O'Brien, W.E. Steinmueller, C. Edquist, S. Metcalfe, B. Coriat, D. Soskice, G. Dosi, B. Dalum, F. Pammolli, M. Mckelvey, L. Orsenigo, W. Garcia, F. Montobbio, F. Lissoni,, N. Corrocher, P. Geoffron, D. Rivaud-Danset, O. Weistein, B. Tether, A. James, M. Harvey, L.D. Adderio, L. Hommen, H. Kettler, J. Wengel, F. Cesaroni, G. Bottazzi, M. Riccaboni.
} 
The paper is organized as follows. In the first part (Section 2) the conceptual framework is briefly presented and the rationale and the basic elements of a sectoral system of innovation and production are examined. Then in Section 3 the main sectoral systems examined are presented and in Section 4 the major trends and challenges in the transformation of European sectoral systems are presented. Section 5 briefly examines which sectoral systems variables affect international performance. Section 6 concludes with some policy implications in a sectoral system perspective.

\section{The building blocks and dimensions of a sectoral system of innovation}

The concept of sectoral systems may prove a useful tool in various respects:

- for a descriptive analysis of the differences and similarities in the structure, organization and boundaries of sectors;

- for a full understanding of the differences and similarities in the working, dynamics and transformation of sectors;

- for the identification of the factors affecting innovation, commercial performance and international competitiveness of firms and countries in the different sectors;

- and for the development of new public policy indications.

In the following pages we will examine the building blocks of a sectoral system of innovation (for a more in depth analysis see Malerba, 2002).

\subsection{Knowledge, actors and networks, institutions:}

\section{the building blocks}

In a sectoral system perspective, a sector is composed of three main building blocks:
a) knowledge and technological domain
b) actors and networks
c) institutions. 
a) Knowledge and technological domain. Any sector could be characterized by a specific knowledge base, technologies and inputs. In a dynamic way, the focus on knowledge and the technological domain places at the centre of analysis also the issue of sectoral boundaries, which usually are not fixed, but change over time. Knowledge and basic technologies constitute major constraints on the full range of diversity in the behaviour and organization of firms active in a sectoral system. Also links and complementarities among artefacts and activities play a major role in defining the real boundaries of a sectoral system. These links and complementarities are first of all of the static type (as input-output links are). Then there are dynamic complementarities which take into account interdependencies and feed-backs, both at the demand and at the production levels. Dynamic complementarities among artefacts and activities are a major source of transformation and growth of sectoral systems, and may set in motion virtuous cycles of innovation and change.

b) Actors and networks. A sector is composed of heterogeneous agents that are organizations and individuals (e.g. consumers, entrepreneurs, scientists). Organizations may be firms (e.g. users, producers and input suppliers) and non-firm organizations (e.g. universities, financial institutions, government agencies, trade-unions, or technical associations), including sub-units of larger organizations (e.g. R\&D or production departments) and groups of organizations (e.g. industry associations). Agents are characterised by specific learning processes, competencies, beliefs, objectives, organizational structures and behaviours. They interact through processes of communication, exchange, cooperation, competition and command. Within sectoral systems, heterogeneous agents are connected in various ways through market and non-market relationships.

Thus in a sectoral system perspective, innovation and production are considered processes which involve systematic interactions among a wide variety of actors for the generation and exchange of knowledge relevant to innovation and its commercialisation. Interactions include market and non-market relations that are broader than the market for technological licensing and knowledge, inter-firm alliances, and formal networks of firms. Often their outcome is not adequately captured by our existing systems of measuring economic output.

The focus on users and on their cognitive frameworks puts a different 
emphasis on the role of demand. Demand is composed of individual consumers and firms characterized by knowledge, learning processes and competencies, and is affected by social factors and institutions. Thus in a sectoral system demand is not seen as an aggregate set of similar buyers, but as composed of heterogeneous agents who interact in various ways with producers. The emergence and transformation of demand play a major role in the dynamics and evolution of sectoral systems.

The types and structures of relationships and networks differ from sectoral system to sectoral system, as a consequence of the features of the knowledge base, the relevant learning processes, the basic technologies, the characteristics of demand, the key links and the dynamic complementarities.

c) Institutions. Agents' interactions are shaped by institutions, which include norms, routines, common habits, established practices, rules, laws, standards and so on, that shape agents cognition and action. They may range from the ones that bind or impose enforcements on agents to the ones that are created by the interaction among agents (such as contracts); from more binding to less binding; from formal to informal (such as patent laws or specific regulations vs. traditions and conventions). A lot of institutions are national (such as the patent system), while others are specific to sectoral systems, such as sectoral labour markets or sector specific financial institutions.

The relationship between national institutions and sectoral systems is quite important in most sectors. National institutions have different effects on specific sectoral systems. For example, the patent system, property rights or antitrust regulations have different effects as a consequence of the different features of the systems, as surveys and empirical analyses have shown (see for example Levin et al.,1987). However the same institution may take different features in different countries, and thus may affect the same sectoral system differently in different countries. Often the characteristics of national institutions favour specific sectors that fit better the specificities of the national institutions. In certain cases some sectoral systems become predominant in a country because the existing institutions of that country provide an environment more suitable for certain types of sectors and not for others. In other cases national institutions may constraint the development or innovation 
in specific sectors or mismatches between national and sectoral institutions and agents may take place. The relationship between national institutions and sectoral systems is not always one-way, as it is in the case of the effects of national institutions on sectoral variables. Sometimes the direction is opposite, and goes from the sectoral to the national level. In fact it may occur that the institutions of a sector, which is extremely important for a country in terms of employment, competitiveness or strategic relevance, end up emerging as national, thus becoming relevant also for other sectors. But in the process of becoming national, they may change some of their original distinctive features.

\subsection{The dynamics and transformation of sectoral systems}

As mentioned in Section 1, during the evolution of sectoral systems change may occur in the technological and learning regimes and in the patterns of innovations. Over time, the knowledge base of innovative activities may change in different ways, for example, evolving towards a dominant design or having a drastic change. In the first case a growth of concentration and the rise of large dominant firms may take place (Utterback,1994). In the second case, new types of competencies may be required for innovation, with major industrial turbulence, entry of new firms and turnover in industrial leadership (Jovanovich \& McDonald, 1994; Tushman, 1986; Henderson \& Clark, 1990). Finally, changes in demand, users and applications represent another major modification in the context in which firms operate and may favour the entry of new firms rather than the success of established ones (Christensen \& Rosenbloom,1995). Change over time results in a coevolutionary process of its various elements, involving knowledge, technology, actors and institutions.

\subsection{The local, national and global dimensions}

National boundaries are not always the most appropriate ones for an examination of the structure, agents and dynamics of sectoral systems. Often a sectoral system is highly localized and frequently defines the specialization of the whole local area (as in the case of machinery, some traditional industries, 
and even information technology). In other cases (or at the same time for specific dimensions of a sectoral system, such as for inputs or demand) the relevant geographical boundaries are global.

\subsection{Theoretical bases}

The notion of sectoral system of innovation and production complements other concepts within the innovation system literature (Edquist, 1997) such as national systems of innovation delimited by national boundaries and focussed on the role of non-firms organizations and institutions (Freeman, 1987; Nelson, 1993; Lundvall, 1993), regional/local innovation systems in which the boundary is the region (Cooke et al., 1997) and technological systems and the distributed innovation system, in which the focus is mainly on networks of agents for the generation, diffusion and utilization of technologies and for innovation (Carlsson \& Stankiewitz, 1995; Hughes, 1984; Callon, 1992; Andersen et al., 2001). In a sectoral system perspective, it is recognised that national and regional/local boundaries matter to varying degrees depending upon the specific sector under consideration. Similarly, the sectoral system of innovation approach encompasses and includes the technological system approach, by placing it within the sectoral context and its economic activities processes. And any analysis that takes a particular configuration of technological systems as a "given" risks overshadowing fundamental processes that serve to define these technological systems.

The theoretical and analytical approach from which this paper draws comes from evolutionary theory. Evolutionary theory provides a broad theoretical framework to the concept of sectoral system of innovation and production. Evolutionary theory places a key emphasis on dynamics, process and transformation. Learning and knowledge are key elements in the change of the economic system. "Boundedly rational" agents act, learn and search in uncertain and changing environments. Relatedly, competences correspond to specific ways of packaging knowledge about different things and have an intrinsic organizational content. Different agents know how to do different things in different ways. Thus learning, knowledge and behaviour entails agents' heterogeneity in experience, competences, and organization and their 
persistent differential performance. In addition evolutionary theory places emphasis on cognitive aspects such as beliefs, objectives and expectations, in turn affected by previous learning and experience and by the environment in which agents act (Nelson, 1995; Dosi, 1997; Metcalfe, 1998). A central place in an evolutionary approach is occupied by three economic key processes driving economic change: processes of variety creation in technologies, products, firms and organizations; processes of replication, that generate inertia and continuity in the system and processes of selection, that reduce variety in the economic system and discourage the inefficient or ineffective utilization of resources. (Nelson, 1995; Metcalfe, 1998). Finally, for evolutionary theory aggregate phenomena are emergent properties of far-from equilibrium interaction and have a metastable nature (Lane, 1993). For evolutionary theory the environment and conditions in which agents operate may drastically differ. Evolutionary theory stresses major differences in opportunities conditions related to science and technologies. The same holds for the knowledge base underpinning innovative activities, as well as for the institutional context. Thus the learning, behaviour and capabilities of agents is constrained and "bounded" by the technology, knowledge base and institutional context in which firms act. Heterogeneous firms facing similar technologies, searching around similar knowledge bases, undertaking similar production activities and "embedded" in the same institutional setting, share some common behavioural and organizational traits and develop a similar range of learning patterns, behaviour and organizational forms (Nelson \& Winter, 1982; Malerba \& Orsenigo, 1996).

One last remark regards boundaries and disaggregation. This issue may refer to sectors and subsectors, agents or functions. The appropriate level of analysis in terms of sector, agents or functions depends on the specific research goal. For example, sectoral systems may be examined in a narrow sense in terms of a small set of product families or in a broad way. In addition to firms and non-firms organizations, also agents at lower and higher levels of aggregation may be the key actors in a sectoral system. Similarly, for analytical purposes one could examine separately a sectoral innovation system, a sectoral production system and a sectoral distribution-market system, which in turn could be related more or less closely. 


\section{An initial typology of sectoral systems in Europe}

How could we characterize the sectoral systems examined in ESSY?

Biotechnology and pharmaceuticals are characterized by major roles of science, networks, division of innovative labour and universities, venture capital and national health systems. Several actors are the protagonists of innovation: large firms, new biotech firms (NBF) and small firms. In this sector regulation, IPR (Intelectual Property Rights), national health systems, and demand play a major role in the innovation process. Now, a wide variety of science and engineering fields are playing important roles in renewing the search space for this sector. New biotech firms have entered into the sector, competing as well as cooperating (or being bought up) with, the established large pharmaceutical firms. More recent changes in regulation and demand are squeezing the profitability of firms and opening up new opportunities in generic drugs.

Telecom equipment and services are characterised by the convergence of different technologies, demand and industries; by a key role of knowledge integration and combination; and by major production specialization. The wide variety of different specialised and integrated actors involved in innovation, ranging from the large telecom equipment producers to the new telecom service firms is due to the process of convergence of previously separated sectors such as telecom, computers, media, and so on, and by the processes of privatisation and liberalisation. In this broad sector innovation is very much affected by the institutional setting and by standards.

Chemicals on the contrary are characterized by the continuity of large multinational firms through R\&D, scale and scope and the emergence of vertical division of labour. Internal R\&D has been complemented by external links and the absorption of external sources of scientific and technological knowledge. The major innovators have shown great continuity in their innovativeness due to economies of scale and scope, cumulativeness and path dependence, as well as research and commercialisation capabilities.

Software has a highly differentiated knowledge base, several different subsectors, firms innovative specialization, user-producer interaction, global as well as local innovation and production systems, advanced human capital mobility. 
In software the context of application is relevant for innovation. The role of large computer suppliers in developing integrated hardware and software systems has been displaced since the early 1980s, with the spread of networked computing, the Internet, the development of open system architectures and the growth of web-based network computing. A lot of specialized software companies innovate either in package software, or in customized software. Here the role of the university is important in the open source domain. IPR play a major role in innovation and competition. Standard setting alliances support common standards in order to facilitate the diffusion and adoption of large integrated systems.

Finally, machine tools have an application-specific knowledge base; firms specialization and user-producer interaction, the extensive presence of local innovation and production systems and a key role played by in-house experienced human capital, on the shop floor level and with applied technical qualification. Products are increasingly being modularized and standardized. Suppliers of components are involved in innovation. Regional clusters are very important. Thus localized user-producer interaction, learning spillovers across producers, national differences in the structure of demand lead to international differences in the rate and direction of the new technology.

\section{Challenges for sectoral systems of innovation}

Sectoral systems face new challenges in terms of knowledge and learning processes, actors and networks and institutions.

\subsection{Knowledge at the base of innovative activities is changing continuously; this change is affecting the boundaries of sectoral systems}

In terms of knowledge base and learning processes, some common trends may be identified.

- First of all, the features and sources of knowledge continue to be different from sector to sector, and show major changes.

- Second, knowledge is relevant for an explanation of the rate and direction 
of technological change, the organization of innovative and production activities and the factors at the base of successful performance.

- Third, both science and development activities are gaining importance in all sectors.

- Fourth, the boundaries of several sectoral systems are changing over time, as a consequence of several dynamic processes related to the transformation of knowledge as well as to the convergence in demand and the changes in the type of competition.

In the pharmaceutical sectoral system the advent of molecular biology since the 1980s has led to a new learning regime based on molecular genetics and rDNA technology, with two search regimes: one regarding cospecialised technologies, the other generic technologies. Nowadays no individual firm can gain control on more than a subset of the search space. Innovation increasingly depends on strong scientific capabilities and on the ability to interact with science and scientific institutions in order to explore the search space (McKelvey \& Orsenigo, 2001; Henderson et al.,1999).

In the telecommunications equipment and services sectoral system the knowledge base is rapidly changing and expanding, with increasing functional differentiation, due to the convergence of information and communication technologies, traditional telecommunication and Internet, fixed Internet and mobile communication, different types of receiving devices such as third generation cellular phones for Internet, desktop computers for telephone calls, palm tops for Internet, etc. (Edquist, 1997). Moreover subsectors such as fixed communications (Dalum \& Villumsen, 2001), satellite communications (Dalum, 2001), mobile phones (Hommen \& Manninen, 2001) and Internet services (Corrocher, 2001) present different features. With the Internet and its open network architecture, modular components and distributed intelligence, both the knowledge base and the types of actors and competences have changed significantly (Corrocher, 2001).

In the chemical sectoral system advances in chemical disciplines such as polymer chemistry and chemical engineering have created the base for greater codificability of knowledge. In the same time firms' behaviour has enhanced the transferability of chemical technologies. Separability and transferability made 
possible the transaction of technology in the chemical industry and the emergence of new markets for engineering and process design services for chemical plants. This type of knowledge base has implied that internal R\&D is increasingly complemented by external links and knowledge. Nowadays in chemicals innovation requires the interaction between $\mathrm{R} \& \mathrm{D}$ capabilities and external sources of scientific and technological knowledge (Cesaroni et al., 2001; Arora et al., 1998; Freeman, 1982).

The software sectoral system has a quite differentiated knowledge base, with extended complementarities. Here the knowledge refers both to the controls of operations of the computer system providing the platform for the different functionalities and the software employing these functionalities. However the boundaries between operating systems and application software are becoming blurred, because of the dynamics of the inward and the outward integration of software functions, upward from system level software to the user interface and inward from software designers closer to the definition of system resources (Steinmueller, 2001). The strength of the forces favouring the creation of generic platforms (and therefore internationally dominant platform suppliers) is moderated by the continuing need for variety generation in the organizations producing the sub-systems that allow these platforms to be customised, the potential for new methods for "platform" creation (based upon the use of the Internet as a tool for collaborative innovation and the distribution of software products), the identification of emerging areas where dominance in "platform" creation remains contestable (such as embedded software), and the identification of areas of the software industry that do not follow the "platform" model and remain in a pre-dominant design state of variety generation such as multimedia software. Much of the innovative challenge of the software industry therefore involves design innovation, not only of the basic operations of the information processing "machine" defined by software, but of the very conceptualization of the information that needs to be processed. Nowadays the three broad subsectors in which software could be examined require different types of knowledge and learning processes. Global package software products are characterised by search for generic solutions, experience as a major input for innovation and a key role of process innovation. Situated and embedded software on the contrary have knowledge related to specific contexts and specialised purposes. Middleware 
software and integrated software solutions - such as product data managers (PDM) and enterprise resource planning (ERP) - aim to reach many users but focus on situated specific applications. (Steinmueller, 2001; D'Adderio, 2001; Mowery, 1996; Torrisi, 1998.)

In machine tools innovation is increasingly systemic. Knowledge about applications is very important, and therefore user-producer relationships as well as partnerships with customers are common. The knowledge base has been embodied in skilled personnel on the shop floor level with applied technical qualification and in design engineers not necessarily with a university degree but with long-term employment perspectives in the company. Internal training (particularly apprenticeships) is quite relevant. However, knowledge building and maintaining in this way is challenged by economic/financial pressure from one side and by labour market restrictions (currently represented by a strong competition on experts) from the other. In small firms R\&D is not done extensively and $\mathrm{R} \& \mathrm{D}$ cooperation is not common. Recently, the knowledge base has shifted from purely mechanical to mechanical as well as microelectronic based and information intensive, with an increasing codification and an increasing use of formal R\&D. Products have increasingly been modularized and standardized. A key role is also played by information flows about components among producers of different technologies, such as lasers, materials or measurement and control devices. (Wengel \& Shapira, 2001; Mazzoleni, in Mowery \& Nelson,1999).

\subsection{Changes in the knowledge base change the types of relevant actors and the structure of networks in a sectoral system}

- The changes in knowledge and learning processes discussed above imply major changes in the organization and characteristics of R\&D. In most sectors R\&D is increasingly decentralised, externalised and internationalised (Coriat \& Weinstein, 2001). This is in relationship with an increasing focus on market oriented $\mathrm{R} \& \mathrm{D}$, the growth of external sources in knowledge and the need to obtain access to knowledge about markets or key technological or scientific resources. (Coriat \& Weinstein, 2001). The organization and the features of R\&D have greatly differed across groups of sectors. While in chemicals and pharmaceuticals large scale internal R\&D 
plays a major role with key links with universities, the emergence of biotechnology leads to an increasingly role of science and to networks of R\&D projects between large pharmaceutical firms, new biotechnology firms and universities. In other sectors such as telecommunications and software $\mathrm{R} \& \mathrm{D}$ requires the integration of different competencies and sources, while in machine tools little formal $\mathrm{R} \& \mathrm{D}$ is done in most small and medium size machinery producers and with most of the action taking place on the shop floor and through embodied in experienced human capital (Coriat \& Weinstein, 2001).

- A rich, multidisciplinary and multisource knowledge base and a rapid technological change implies a great heterogeneity of actors in most sectors.

- Demand as composed by users and by consumers is a major factor in the redefinition of the boundaries of a sectoral system, stimulus for innovation, factor shaping the organization of innovative and production activity. In addition, the emergence of new demand or the transformation of existing demand is the major element of change in sectoral systems over time.

- Suppliers and users affect the boundaries of sectoral systems, by making both supply and demand an integrated part of a sectoral system and by greatly affecting sectoral linkages and interdependencies.

- In all sectors universities play a key role in basic research and human capital formation and in some sectors (such as biotechnology and software) also they are a source of start ups and even innovation.

- In software or biotechnology-pharmaceuticals new actors such as venture capital have emerged over time.

In pharmaceuticals and biotechnology the change in the knowledge base has led to a different organization of innovative activities within and across firms and a division of labour between NBF (lacking experience in clinical testing) and established companies. Networks of collaborative relations facilitated by the science base and by the abstract and codified nature of knowledge generated by the NBF, have emerged in the sector. Also mergers and acquisitions allowed established firms to obtain complementary knowledge for the development of innovative products. As of now, the pharmaceutical-biotechnology sectoral system has a structure of innovative actors which includes large firms, NBFs, small firms, and 
single individuals (such as scientists or NBF entrepreneurs), complemented by a very rich set of non-firm organizations and institutions, ranging from universities to the public and private research systems, the financial system and venture capital, the legal system and IPR. Demand channelled through agencies, physicians and the health system, and institutions such as regulation play a significant role in the diffusion of new drugs. Nowadays no individual firm can hope to gain control of more than a subset of the search space. Even the innovativeness and competitiveness of the largest pharmaceutical firms depends on strong scientific capabilities and on the ability to produce and interact on one side with science and scientific institutions (in order to explore such a complex space) and on the other with specialized innovative firms (in order to develop new products) (McKelvey \& Orsenigo, 2001).

In telecom equipment and services, convergence and expansion of the knowledge base allow for the presence of a wide variety of actors, coming from previously separated industries, each one emphasising different sets of competencies. For example, in telecommunication equipment and networks firms may range from incumbent telecom equipment suppliers and incumbent network operators, to new entrants telecom operators, cable TV operators and alternative network providers (Dalum \& Villumsen, 2001). In Internet services, firms may range from Internet service providers, to Internet content providers, e-commerce companies and software and Internet specialised consulting companies. Specialised competencies and specific knowledge have increasingly become a key asset for firms survival and growth, but even more important in the new telecom environment is the combination of existing and new competencies - software programming, network management, content provision - which traditionally belonged to different companies (Corrocher, 2001). Also in this sector networks among a variety of actors, not only firms, but also standard setting organizations and research organizations, are relevant. Demand plays a key role not just in terms of user-producer interaction, but also in terms of emerging characteristics. This is particularly true in the Internet services sector, where the changing requirements of the final users - from standardised services like Internet access and e-mails, to more complex applications such as Intranets, Extranets and platforms for electronic commerce - have stimulated firms to upgrade the quality of services. 
In chemicals, the increasing reliance on external links for complementary scientific and technological knowledge has led to the emergence of networks of three types: interfirms, university-industry and user-producers in specialty segments. The relevant networks have changed in relation with the type of knowledge base. For example, in polymer chemistry and with the diffusion of chemical engineering, networks between producers and users, industry-university networks, and vertical networks between chemical companies and engineering contractors are common, with the use of mergers and acquisitions to related and unrelated sectors in order to acquire capabilities (Cesaroni et al., 2001).

In software the changing knowledge base and the blurring boundaries between operation system and application software has created an evolving division of labour among users, "platform" developers and specialized software vendors, and a further tension between horizontal integration and specialization. The historical role of computer producers has largely been displaced by a division of labour between software and hardware "platform" producers, each of which is governed by the needs of the other as well as the challenge of preserving market position. This can be characterised in the case of the personal computer by the existence of a large installed base with specialized applications and operating system software with high switching costs (Bresnahan \& Greenstein,1996). The sectoral system of innovation in software, however, is incomplete without the addition of companies that utilise these platforms to deliver enterprise-critical applications. Many of these applications continue to be self-produced by organizations using the tools provided as part of the platform or available from the development tools markets. It is also true, however, that the generic platforms are creating a market for specialised software producers whose outputs are aimed at the customisation of the needs of a particular class of users. In some software subsectors, such as embedded software, this division of labour is particularly high but appears to be threatened by the needs for more consistent and reliable approaches that can only be achieved by concentrating development resources in the production of software platforms (Steinmueller, 2001). By contrast, in the enterprise resource planning and open source software sub-sectors, variety generation is being accompanied by a growing diversification of the actors and ever more complex network relationships among them, a development that also suggests a specific need for the development of new university and public research organization 
involvement in supporting the knowledge infrastructure for such developments. (D'Adderio, 2001). In entreprise software a transformation in demand by large industrial users is emerging. However, as the competencies required by enterprise systems are so extended that no one supplier can master the entire range required to satisfy demand in all industry and non-industry sectors, scope is created for the growth of specialised niche software producers and systems integrator firms to prosper (D’Adderio, 2001).

In machine tools firms are highly specialized and focussed on specific vertical segments. Networks here differ from country to country, because the types of products and the different users and demand structures have led to different sectoral systems, each of which has been innovative in its own way. In any case, local financial organizations and vertical links with users play a major role. While "old" actors (industrial and professionals' associations, specialized university and research institutes, prime user firms, producers, traditional suppliers, etc.) still dominate, "new" actors occur on the horizon (such as "communities" related to specific technological shifts fuel cells, nano technologies). Market mechanisms increasingly show up in yet "non-market" relationships, such as the co-operation in industrial/professional associations, or special customer-supplier interactions in the machine tool sector. And industry public-private consortia increasingly complement the latter. (Wengel \& Shapira, 2001)

\subsection{The role of national as well as sector-specific institutions is relevant for innovation}

- Institutions play a major role in affecting the rate of technological change, the organization of innovative activity and the performance of sectoral systems in all ESSY sectors.

- But each sector has a different set of relevant institutions, often the outcome of the interplay between sectoral and national variables (Casper $\&$ Soskice, 2001; Coriat \& Weinstein, 2001).

- Some of these institutions are national, but with different effects on innovation and performance according to the sector or the country.

- Other institutions are sector specific. 
In pharmaceuticals health systems and regulations play a major role in affecting the direction of technical change, in some cases even blocking or retarding innovation (Lacetera \& Orsenigo, 2001). In addition, the form of corporate governance is closely related to the country of origin: the outsider system in UK and insider system in Germany, with France in between (Geoffron \& Rubinstein, 2001). Finally patents have played a major role in the appropriability of the returns from innovations.

In chemicals patent policies still play a critical role, particularly for small firms. Indeed, proper forms of intellectual property rights and strong enough patent protection support the activity of smaller technology-based firms and create the bases for a division of labour between technology suppliers and users (and allowing for the development of markets for technology). This pattern is particularly evident in the US, where patent protection has been properly defined earlier on.

In software IPR play a major role in strengthening appropriability, and have been greatly affected by the emerging open source movement. In addition, standards play a major role (Steinmueller, 2001). Standard development organizations, country and industry consortia, (such as PDES and ProSTEP), and standards-setting alliances, (such as the Object Management Group) are very important. Networks of users also play an increasingly important function, as the involvement of the Manufacturing Domain Task Force in the development of standards for PDM software illustrates. Users also often gather around user mailing lists (i.e., the IPDMUG for PDM software): these are used as vehicles to test and compare the performance and capabilities of competing software products (D’Adderio, 2001).

In machine tools, internal and regional labor markets and local institutions (eg. local banks) play a major role in influencing innovation and international advantages of specific areas. There are differences in this institutional base. For example, in the UK and the US, formal and informal institutional support for machine tool companies has typically been "thinner" than in Japanese, German, and Italian regions. Trust-based, close relationships on the regional level have obviously over a long time ensured a sufficient financing of the innovation and expansion plans of the mostly family businesses in Germany and Italy. In Germany vocational training has greatly fostered the development of skills in the machine 
tools industry. The "Maschinenbau-Ingenieur" (mechanical engineer) in the German higher education system went along with the predominance of mechanical innovation. Rather stable employment conditions and company employment strategies (internal labor markets) formed the background for cumulative knowledge building and incremental innovation (Soskice, 1997). Standards are a key institution in the machine tool sector, with a long tradition with respect to health and safety but also with respect to economies of scale, building a basis for the share of development tasks between the machine tool makers and the suppliers of components and periphery equipment. The EU machine directive was fundamental for the realisation of the Common Market, particularly in the machine tool industry. The "self certification" or relatively open definition in the directive turned out in favor of the already internationally more competitive companies rather than to open up competition. (Wengel \& Shapira, 2001).

Finally, in telecommunications the role of regulation, liberalization/ privatisation and standards have played a key role in the organization and performance of the sector. As discussed in Dalum and Villumsen (2001) liberalization and privatization has had major effects on the behaviour and performance of incumbents and has transformed the structure of the industry. An example of the role of institutions is given by GSM, a standard which has played a major role in innovation and in the success of GSM in Europe. In particular, concerted standard settings, European and open standards have proven a major driving force.

\subsection{The coexistence of global, national and local boundaries is present in most sectoral systems}

In sectoral systems the national, the local and the global dimensions coexist. In the pharmacetuical and biotechnology sectoral system European countries exhibit differences in terms of national institutions, demand, networks of knowledge acquisitions, etc., and such national differences have appeared to historically affect the national firms (McKelvey \& Orsenigo, 2001). Over time, the markets for knowledge as well as the markets for products are becoming increasingly international, as are regulations and scientific and technological knowledge flows. Nevertheless, national institutional arrangements appear to 
influence not only the number and types of biotechnology firms started but also their specialization into different areas, as evidenced by differences between Germany and the UK (Casper \& Soskice, 2001).

The chemical sectoral system has always been global, and for many years the industry has shown considerable flows on international investments, and systematic flows of engineering and process licenses. While up to the 1980s foreign investments were to a large extent confined to first world countries, in the recent decades there has been an increase in the flows towards the developing countries as well. Analyses of investment flows (Arora et al., 1998) show that the European chemical industry has moved abroad its investments. The same can be said of the American and Japanese chemical industry. This means that there has been an increasing globalisation process for this industry, that can be translated into a significant increase in the number of chemical plants built in Asia. In general, it can be said that there is a trend toward the location of plants near the customers and the fast-growing regions, where the demand and consumption may be stronger. This trend might be related to an increase in product differentiation and customization of plants, together with an increased concern on reducing transport costs.

In software the global (for global software products) and the local dimension (for situated application software) coexist. In middleware software such as enterprise software global players, while centralising R\&D activities, are forced to address the needs of customers at the local level, by locating near key customers in order to acquire industry - sector — and firm-specific (user) knowledge (D'Adderio, 2001). An increasing trend sees the configuration of individual new software modules according to geographical determinants such as the features of a leading market (i.e., the creation of SAP's* "campus management" module for universities according to the features of the dominant US market). Such a (local) module is then used as a (global) standard and implemented across all other universities worldwide which are adopting SAP. This suggests a cycle of adaptation and a continuing tension between the local and global levels and vice-versa, corresponding to the tension between greater generality and greater customisation of the software product (D'Adderio, 2001).

* Systemanalyse and Programmentwicklung - Sistemas, Aplicações e Produtos para Processamento de Dados. 
Machine tools are often local in the organization of supply although they are global in terms of demand and outputs. Data from the Fraunhofer ISI manufacturing innovation survey 1999 in Germany on mechanical engineering underpins that while the input comes to almost one third from suppliers within 50 kilometers, only little more than 10 percent of the output is delivered to customers within the region. Similar figures will be observed when the border is set at the national level. The same variety holds for knowledge flows, which could range from the very local to the very global (see Breschi \& Lissoni, 2001). The recruitment of skilled shop-floor personnel is usually a local activity. Many institutions relevant to the sector are national (such as the educational system), while others mainly European (though with strong national forces such as standards) (Wengel \& Shapira, 2001).

\subsection{Coevolutionary processes are taking place in all sectoral systems}

Changes in the knowledge base or in demand affect the characteristics of the actors, the organization of $R \& D$ and the innovative process, the type of networks, the structure of the market and the relevant institutions. All these variables in turn lead to further modifications in the technology and the knowledge base and demand, and so on.

In pharmaceuticals, the interaction between knowledge, technology, firms, institutions shapes the evolution of the system of innovation. On the one hand, the changes in the knowledge base and in the relevant learning processes of firms induce deep transformations in the behaviour and structure of the agents and in their relationships among each other. On the other hand, the specific ways these transformations have occurred across countries are profoundly different, due to details of the institutional structure of each country (McKelvey \& Orsenigo, 2001). As an example, product approval regulations inserted an incentive towards more innovative strategies, at least for those firms and countries which had the capabilities to invest in the new technologies. Similarly, weak patent protection induced imitative strategies, but this effect was much less important for firms and countries which had developed strong technological and scientific capabilities (as for example Germany until the advent of the 
molecular biology revolution). Conversely, the introduction of stronger patent protection might have contributed to the virtual disappearance of the Italian industry, which was until the mid-seventies one of the most successful producer of generics. As a final example consider how the molecular biology revolution, by creating new competencies and a new technological regime, induced deep changes in the incentive structures within firms, universities, etc. (McKelvey \& Orsenigo, 2001).

In chemicals, processes of coevolution of technology, demand, markets, agents and institutions have also been present. One interesting example of coevolutionary process in chemicals is related to the environmental issue. Greater attention paid by consumers to pollution and environmental problems result in three different, but related consequences. First, all developed countries assist to the rise of new markets for environmentally-safe, less pollutant products. Second, governments pay greater attention to pollution, and try subsequently to impose regulations and define appropriate control measure, in order to reduce waste production and pollution. Third, as a consequence of both forces, chemical firms have to develop and adopt new production technologies (environmental technologies, green processes), and new products (e.g., less polluting solvents and paints). Moreover, rigid environmental standards and strong public pressure have a positive influence on the environmental innovative rate of chemical firms. Another consequence of the growing attention to environmental issues is the birth of an intermediate market for environmental technologies and engineering services related to environmental technologies. Similarly to the birth of SEFs providing process technologies in chemicals, new environmentallyrelated SEFs have started to operate (especially in the US), and a new market for environmental technologies and engineering services is about to emerge (Arduini \& Cesaroni, 2001).

In machine tools a major driving force for coevolutionary processes is the demand from advanced customer sectors, namely the automotive, aeronautics and defense industries. However the recent disillusionment from high automation (CIM, manless factory), the engagement in new production concepts ("lean production", teamwork, TQM, etc.), the growing environmental concerns, as a consequence the dominance of incremental innovation, more market like user-relationships and the key role of product accompanying services. Another 
coevolutionary process can be observed in the context of technological developments, namely in electronics, new materials, micro or nano technologies. Electronic devices have an increasing share of the value of machine tools and IT technologies (PC, operating systems, Internet) and often determine technical solutions on how to control machine tools and on how to integrate them in company production systems. As a consequence, besides electrical engineers, computer scientists partly replace mechanical engineers in the design departments of machine tool manufacturers. Some firms have followed strategies of outsourcing. On the shop-floor level a related change in required qualifications took place. New apprenticeships were developed (eg. "Mechatroniker") others are disappearing. However the institution of the "Facharbeiter" in Germany do not seem at risk. Links to basic research are now looked for and patenting is growing. Sector-specific associations start cross-sectoral activities and joint organizations.

In software since the early 1980s, the spread of networked computing, embedded software, the Internet, open system architectures, open source and web-based network computing has led to the decline of large computer producers as developers of integrated hardware and software systems and the emergence of specialized software companies and an increasing role of the university in open source. This in turn has led to the expansion and growth of several software subsectors, each of which has different types of products, firms and capabilities Moreover also software distribution has greatly changed accordingly from the licensing agreements in the early days: now there are independent software vendors, price discounts for package software, and, with the diffusion of the CD-ROM and the Internet, shareware and freeware (this last one particularly relevant with Linux) (D'Adderio, 2001). In the enterprise software sub-sector higher demand for integration by user organizations reinforces the role of existing actors (i.e., large producers of standardised integrated software solutions) as well as creates in scope for new actors (i.e., systems integrators, specialised niche applications producers and software implementation consultants) (D'Adderio, 2001). The increasingly generic nature of large systems also creates a greater need for customization whereby customer knowledge and requirements become an important source of input into the development of new or revised modules. In response to the increasing 
need for customization, large software producers pursue a higher level of internal specialization by creating sub-units that address a specific market segment and compete for resources with other units.

In telecom equipment and services convergence and the emergence of Internet originates a more fluid market structure with a lot of different actors with different specializations and capabilities, and new types of users. This in turn greatly expands the boundaries of the sector by creating new segments and new opportunities, and also national differences in the organization of innovation Moreover, the emergence of Internet generates more pressure in favour of open standards and leads to the rise of new actors such as ISP and content providers.

Coevolution leads to the emergence of new activities as a process of fusion, such as ICT and audio-visual technologies (Corrocher \& Malerba, 2002). Within this context, the fusion may occur at different levels. The fusion of technologies drives a transformation of the existing activities into hybrid activities, which span across different technological fields and even across different industries. Often technology fusion concerns the emergence of "new-science"-based technologies through the combination of older sciences with the rapidly expanding capacities of information technology to store, manipulate and transfer an increasing amount of digital information. Automatic Speech Recognition and Natural Language Processing constitute two examples of these new technologies (together with computational chemistry, computational fluid dynamics, geographic information systems, remote sensing and neural networks) (Mahdi \& Pavitt, 1997; Koumpis \& Pavitt, 1999).

The prospering of these new-science based technologies is strongly determined by the rapid progress in the area of ICT. Their early exploitation has occurred both within very large, multi-technology firms exploring future options, and within very small firms investigating the opportunities emerging from research in universities. In this respect, there is a general trend related to this type of technology fusion, i.e. the direct involvement of university-based research and related small-firm spin-offs, which increasingly originate from the universities, in the initial development of fundamental and pervasive technologies. Recent advances in the science of molecular biology and in the technology of information processing reduce the costs of search and 
experimentation for specific technical problems and their solutions, making it easier for universities themselves to contribute effectively in certain fields to development as well as to research activities (Koumpis \& Pavitt, 1999).

Technology fusion appears to be particularly high in telecommunications, information technologies and Internet services. The process of fusion between these industries generates hybrid activities, whereby the services providers exchange knowledge and competencies on a continuous basis with manufacturers of high-tech products. There is a close and symbiotic relationship between services and manufacturing, so that the distinction between the two has become blurred and sometimes arbitrary. One could ideally envisage the result of the fusion of manufacturing and service knowledge in the activities related to the ICT as a platform, which represents a combination of hardware, software and specific knowledge of the service end user market. In this case, the interaction has as a main result the fact that specialized applications provide the basis for the development of specific hardware platforms. At the same time, technology plays an important role in the evolution of information-intensive service providers, since these firms rely upon technological platforms to deliver their services. Furthermore, the growth of multimedia and new digital media has significant implications for the emergence of new types of equipment and local infrastructure, in that the network structure will ultimately be determined by the availability of information services (Mansell \& Steinmueller, 2000).

In the telecommunications networks for business data, the increasing technical advancements in the infrastructure and the process of deregulation make the range of services provided in the market more complex and wider. In this context, network operators have traditionally collaborated on a continuous base with manufactures suppliers for the design of switching, transmission and terminal equipment. Turning to a different example, electronic commerce is often conceived in terms of the "dis-intermediation" of wholesalers, retailers, and other economic agents to provide direct marketing of goods or services to final customers. Although electronic commerce is not a widely recognised source of interactive relationships between manufacturers and service companies, in areas requiring more innovative and specialist inputs, a new set of intermediaries is established, centered around the Internet and web-based ventures. Although most electronic commerce services are based upon "hard" technological 
innovations focused around a series of ICT platforms, non-technological serviceoriented innovations are also quite important in the development of new activities. The new intermediaries are focusing on the establishment of innovative forms of access routines, creating secure (encrypted) communication, the design and effective establishment running of web site and portals (Howells, 2000; Corrocher \& Malerba, 2002).

\section{International preformance seen through the lenses of sectoral systems}

What about the relationship between specific dimensions of sectoral systems and the international innovative performance of firms and countries? Some remarks may be advanced in this respect.

- In several sectoral systems differences between European countries, the United States and Japan in the sources of knowledge, types and competences of actors, networks and institutions greatly affect differences in these countries' international performance.

- The lack of success of some European countries in some sector has been due to problems and deficiencies in their sectoral systems.

- Even within the sectors in which Europe does not fare well, those European countries that specialize in subsectors with products, knowledge and institutional requirements that match their specific institutional framework are successful.

A very brief discussion of the sectoral systems examined illustrate this point (for a longer discussion see Coriat et al., 2002). In chemicals international performance is related to ability of large multinational firms to perform $R \& D$, to build efficient networks (with universities or with specialized suppliers), to expand and to adapt to the changing knowledge base. Accordingly, their location depends upon regional characteristics including local demand and technological and scientific research capabilities. Finally patent policies are particularly important in support of the activity of smaller technology-based firms. In the US a division of labour between technology suppliers and users, and the 
development of markets for technology has taken place. By contrast, European markets for technology are far from being developed, and this requires policy support for their formation, firstly (but not only) in terms of policy for intellectual property rights.

In pharmaceuticals and biotechnology the main factors affecting industrial leadership are a dynamic combination of many aspects: a strong science base created upon a high quality and efficient organization of research and education (for scientists, entrepreneurial scientists and managers), a tradition in the university-industry relationship and transfer, the presence of a market for technologies within clear institutional (patent legislation) and regulatory frameworks. The size of the domestic market, its degree of competition and integration are also important in an industry with high fixed cost in R\&D. It also facilitates the creation of alliances between small and big firms and an efficient division of labour. US has been able to become leader in biotechnology at the end of the 70s and beginning of the 80s thanks to the excellence of its scientific base and to firms start-ups, a combination of university spin-off, scientists, professional managers, venture capital. Geographical proximity played a major role. It is interesting to note that in UK there are most of the necessary factors conducive to the expansion of biotechnology outlined above. Nevertheless, despite being the first to develop in Europe, UK biotechnology is stagnating and only one firm has been able to launch a therapeutic product in the market. Lack of expertise at the level of scientists, managers and also technology transfer offices in universities seem to be one of the main constraining factors.

However, in Europe, as Casper and Kettler (2001) and Casper and Soskice (2001) show, European countries may end up specializing in subsectors of biotechnology. In Germany biotechnology firms specialize into platform technologies that are then sold to other research laboratories (for example consumable kits to rationalize common molecular biology laboratory processes). These technologies are more generic and more cumulative than the standard therapeutic products, often relate to the development of equipment for pharmaceutical firms, have library of core technologies that are then customized for specific market niches. These features fit better than the standard therapeutic products with the German institutional framework (characterized by "insider" corporate governance, internal long term relationships between firms and 
employees, investments in firms specific knowledge). On the other hand, firms in the United Kingdom specialize in standard therapeutic products which are related to the standard products developed by the dominant American industry (Casper \& Kettler, 2001; Casper \& Soskice, 2001).

In software, European packaged software suffers primarily from the first mover effects of the US industry stemming from the personal computer revolution and the effects of network externalities in software. In US federal government, military and social security system investments played also an important role stimulating research in universities, creating infrastructures and enhancing the supply of skilled personnel. In Europe fragmented markets were a significant constraint and the industrial, university and public research systems displayed feeble support to the development of personal computer applications. Those segments that are less affected by these factors are also the ones where there are closer and more important ties to local content or business practice (integrated system software and multimedia software as well as the large "hidden" sector represented by in-house development and related system integration and consulting businesses). Open source software is an emergent area of European participation and expertise, which offers considerable promise in revitalising European systems integration and consulting activities. Of all of the software sectors examined for the ESSY study, the embedded system software market appears to show the clearest signs of a dysfunction as a sectoral system of innovation in Europe and presents the clearest case for intervention in the form of new interdisciplinary research programmes and a dialogue with industry concerning their future needs.

In telecommunication equipment and services European performance is weak. In other telecom segments like mobile phone and some Internet services European firms are performing reasonably well. The good performances of some European countries are the results of specific demand conditions and of historically contingent procedures of European standard setting backed by national telecommunications providers (then public monopolies). Since a large market is created European firms can retain an advantage through learning effects and innovation on the production side. In order to do so they should have the appropriate level of skilled human resources.

However, as Casper \& Soskice (2001) noticed, recently in the telecommuni- 
cation sectoral system some of the institutional features that characterize the Swedish national framework (such as the long term relationships between firms and employees) have been modified in order to take into account the new characteristics of the innovation process in mobile phones. Ericsson recognized that wireless technologies require open standards and the full exploitation of network effects. Thus in the late 1990s Ericsson decided to make its last system integration language open rather than proprietary, and sponsored the formation of new start ups which are spin-offs from Ericsson and which aimed to develop products compatible with Ericsson's new generation of wireless technologies.

Finally liberalization and European integration (with an active competition policy) have improved innovative and economic of European firms. This could be not sufficient if it is not coupled with the development of a critical mass in terms of network of cooperating and competing firms at the European level.

Finally, in machine tools linkages with research centres, producers, and users, and codified knowledge are important and the role of strategic partnership has increased. In Europe in face of the transformation of the knowledge bases and the increased level of international competition, a critical factor is the continuous upgrading of labour and engineering skills. Germany strength continues to be the integration of theory and practice, manufacturing and design. Italian firms have greatly upgraded their human capital in terms of external formal training. The increasing relevance of science and subsequent increasing distance of the $\mathrm{R} \& \mathrm{D}$ and design processes from the production area may threaten this strength (Wengel \& Shapira, 2001). In this respect, it is interesting the double effect of niche user-supplier interaction. On the one side it helps preventing strong competition from standardized low cost general purpose technologies. This is particularly true in EU. On the other side it prevents the growth of a market leader. This is recognized as one of the major causes of the US decline in these industries. For EU it can be worthwhile asking if this pattern is stable or not, if there are risks of loosing the positions of leadership and which are the possible outcomes of the process of economic integration (Mazzoleni in Mowery \& Nelson, 1999). Strong regional sectoral linkages and a close coupling of regional production complexes with users will likely continue to be key elements in competitive advantage in machine tools, as in the past. However, increased investments in system integration, innovation and emerging technologies, public- 
private collaboration, formal training systems, technology and market intelligence, and international partnerships and linkages are also likely to characterize the most successful elements of the sector in future years.

In addition to the specific coevolution between firms' capabilities and the knowledge bases, actors and networks and institutions of a sector, are there common determinants of industrial leadership?

a) Technological and scientific research capabilities. In some ESSY sectors technological and scientific research capabilities and education are major sources of industrial leadership. Success stories are a combination of the ability of creating new products opening up new disciplines and markets and, at the same time, integrating research, teaching and industrial needs. Importantly the construction of a solid knowledge and scientific base in specific fields has often benefited from different forms and levels of public investments in their early stages (i.e. pharmaceutical, biotechnology and software), above all in the US. Moreover the integration between in-house research and advancements in the relative transfer sciences (chemical engineering, automation and robotics, computer sciences, biotechnology, microbiology, pharmaceutical chemistry) help firms to be ahead of their competitors product and process technologies.

b) Demand and interactions with sophisticated users. Close and continuous interactions with sophisticated users is particularly important in the case of machine tools and chemicals (and in some segments of software and biotechnology). In machine tools and chemicals also co-location supported the innovative performance of firms. However the mechanisms connecting demand to economic success are different according to the sector. Demand can be important in terms of level (size of the market: chemicals, pharmaceuticals, packaged software), in terms of quality (machine tools in Europe, chemical engineering in US), in terms of composition (software and machine tools in Europe), in terms of specific requirements (machine tools in US and Japan, chemical engineering, telecom), in terms of government share (biotech and Telecom in the US).

The size of the market and its degree of integration has also been a conducive factor of US success in many sectors. EU seems to be penalized by fragmentation in some sectors with low marginal costs (packaged software and pharmaceuticals), and increasing returns to users adoption (segments of packaged software). In these cases fragmentation of markets leads often to different 
monopolies or vertical integrated structures that obstruct the development of technologies (see software, biotech, chemical engineering). At the same time according to the characteristics of the industry, different markets and heterogeneous users help European firms to be ahead of their competitors thanks to their ability to create customized product and process technologies (machine tools and integrated software solutions).

c) Technology and innovation policies. Technology and innovation policies play an important role in affecting the industrial, institutional and organizational settings and the rate of innovative activities. In most of the ESSY sectors, agents have drawn incentives and opportunities from different types of institutional packages: IPR systems, specific norms and laws, types of standards, product approval, government support and corporate governance. Patent policies are particularly important in support of the activity of smaller technologybased firms and university licensing (particularly in biotechnology and chemicals). In the US this has created the bases for a division of labour between technology suppliers and users, and allowed the development of markets for technology. Finally standardization has affected the mobile telephone industry. In particular, European firms widely benefited from the European decision of adopting GSM technology.

d) The stage in industry life cycle and the role of science. Whilst European performance appears to be good or relatively good in "mature" industries and products, even for the most sophisticated parts of these industries, in emerging industries and fields of activities - biotechnology, Internet and important segments of IT's (see McKelvey \& Orsenigo, 2001; Casper \& Kettler, 2001; Corrocher, 2001) - Europe clearly is facing difficulties. First there is a lack of investment in $R \& D$ in the new emerging fields of science and basic research. This is obvious for life sciences for example, if the European investment is compared with the American (cf. Muldur, 2000; Pavitt, 2000a, 2000b). Casper and Kettler (2001) recall that in the case of UK biotech sector, the main problem was not the lack of venture capitalists ready to embark on new biotech start-ups, but the lack of good scientists able to promote this type of firms. When the scientific capacities exist, they seem to be too highly dispersed throughout European universities and territories. Thus no network effect can emerge and structure the right division of labour and efforts able to ensure the promotion of these new activities. One here 
has to remember that in the USA some $80 \%$ of Venture Capitalists' investments are concentrated in two regions: California around Silicon Valley and Route 128. No "regional advantages" (Saxenian, 1994) has yet emerged in Europe in these fields. Close to this point, another argument has to do with the type of educational systems and labour markets prevailing in Europe, specially in the field of high skilled engineers, researchers and the like. Here the relative advantage of European systems (largely based on internal labour markets) seems to turn into a series of relative disadvantages. Insufficient mobility and flexibility in these specialized labour markets makes it difficult for firms engaged in the new emerging fields to find the right skills and to be able to gather the necessary assets to launch new products or services. This is the case of multimedia and Internet, where innovative firms face shortages in the supply side of the labour markets (see Corrocher, 2001). This is an institutional failure (or at least an institutional limitation) of most of the European educational systems, unable to react with sufficient speed and flexibility to the reorganization of the knowledge base and the recombination of disciplines and research fields driven by the scientific and technological revolution opened in IT and life sciences. In conclusion the European difficulties are much more focused. The European problem is: new disciplines, new emerging fields of knowledge and new firms' capabilities for the industrial and commercial exploitation of this knowledge. One has to notice that, in many respects, these difficulties were worsened since the European (or national) authorities have failed to provide "on time" the right non market resources and institutions required to ease the entry into these new fields.

\section{Policy implications}

In a sectoral system perspective the main role of the policy maker is to facilitate the self-organization of the sectoral innovation systems within the relevant policy domain. An important consequence of this is that the policy making process is itself the reflection of bounded rationality and learning in the presence of immense heterogeneity in the phenomena defining innovation and the innovation process. The sectoral system approach is an important alternative to the concept of the optimizing policy maker that characterizes the market failure approach to innovation policy (for a more detailed discussion see Edquist, 1997). 
What, then, are the reasons for public policy intervention in a market economy? As regards, for example, technical change and other kinds of innovations, two conditions must be fulfilled for there to be reasons for public intervention in a market economy. First, the market mechanism and capitalist actors must fail to achieve the objectives formulated. A problem of imperfect self-organization must exist. Second, the state (national, regional, local) and its public agencies must also have or be able to build the ability to solve or mitigate the problem.

The sectoral system of innovation approach can be used as a framework for designing specific innovation policies. The importance of the sectoral system is that it forms the locus of intersection of numerous networks generating particular kinds of knowledge. For example, a technologist in a firm may interact with other technologists in the relevant disciplinary community, with industry and government groups establishing standards and regulations, with technologists in rival firms and with academic researchers in supporting fields. Each of these networks has different members and different purposes but all contribute to innovation. Indeed, innovative ability may depend on the ability to participate in and manage these network relations. Thus, the wider significance of the sectoral perspective is to identify the complex of networks and the dynamics of their birth growth and even decline in relation to innovation performance.

Within a system of innovation framework, an identification of the causes behind the problems is the same as identifying deficiencies in the functioning of the system. It is a question of identifying those systemic dimensions that are missing or inappropriate and which lead to the "problem" in terms of comparative performance. Let us call these deficient functions "system failures". When we know the causes behind a certain "problem" - for example weak technological transfer between university and industry — we have identified a "system failure". Not until they know the character of the system failure, the policy-makers can know whether to influence or change organizations or institutions or the interactions between them - or something else. Therefore, an identification of a problem should be supplemented with an analysis of its causes as a part of the analytical basis for the design of an innovation policy. Benchmarking is not enough. In terms of policy, it is possible to state the principal contributions of the sectoral system approach. 


\subsection{A sectoral system approach provides a new methodology for the study of sectors and therefore for the identification of variables which should be the policy targets}

While up to now industrial economics has focussed on dimensions such as structure-conduct-performance strategy in a game theoretic way, transaction costs or sunk cost and the bounds approach, the approach suggested here is that sectoral analyses should focus on systemic features in relation to knowledge and boundaries, heterogeneity of actors and networks, institutions and transformation through coevolutionary processes. As a consequence, the understanding of these dimensions becomes a prerequisite for any policy addressed to a specific sector.

\subsection{The impact of general or horizontal policies may drastically differ across sectors}

A second point is that the impact of horizontal policies may greatly differ from sector to sector. The channels and ways policies have their effects differ from sector to sector. For example, two of the major policy statements derived from the innovation system approach could be further qualified looking at the different relevance of the following phenomena across sectors.

\section{- Cooperation and networks may have different relevance and characteristics} among sectors. In a sector, the generation and commercialization of innovation is likely to involve extensive co-operation and division of labour, much of which is negotiated in networks rather than governed by ordinary market clearing mechanisms. Here the important shift in policy emphasis towards strengthening innovation systems, organizations and institutions (rather than seeking to influence specific innovation events) has to be supplemented by the understanding of the relevance of the role of cooperation and networks in the specific sectoral system of innovation.

- Non-firm organizations and institutions could have different relevance in different sectors. The institutional setting is very important in a sectoral system and should be monitored by public authorities. For example, the legal and institutional rules governing cooperative exchanges are evolving within existing 
legal frameworks such as those governing intellectual property rights that were devised for other purposes. It is very likely that there will be major unintended consequences stemming from changes in these rules. A sectoral system of innovation is composed of for-profit firms but its performance in any particular sectoral setting is likely to be affected by not-for-profit organizations such as public research institutions and universities. The interactions between all the organizations active within a sector contribute to the sustainability and success of commercial activities within the sector. When the role of public organizations is well understood in the context of the innovation needs of a particular sector, policy can have a major impact in reshaping the missions of existing or in creating new public organizations.

\subsection{The analysis of the rationale and the effects of policies requires a deep and careful comparative analysis of sectoral systems over time and across countries}

As previously mentioned, each sector has different features, organization and dynamics, and the actual outcome is the result of the interplay of the various basic variables affecting a sectoral system and of their interaction over time. Thus establishing a basis for comparative analysis of the configuration of active institutions in any particular sector is a necessary step in policy formulation. These configurations can differ across national or regional contexts, but the effectiveness of variant configurations must be analysed rather than presumed to be sustainable. Finally, different contexts may limit the transferability across borders of sectoral policies and require different interventions.

\subsection{For fostering innovation and diffusion in a sector, not just technology and innovation policies, but a wide range of other policies may be relevant}

A sectoral system approach emphasises that innovation and technology policy are linked with and affect other types of policies, such as science policy, industrial policy, policies related to standards and IPR and competition policy. In addition, a sectoral system approach highlights the interdependencies, links 
and feedbacks among all of these policies, and their effects on the dynamics and transformation of sectors. In fact, the problems that shape innovation arise within the context of the sector, and neither the trajectory of the technology nor the trajectory of the market are independent of one another.

\subsection{The policy maker is an active internal part of sectoral systems at different levels}

The public actor has to be aware that he or she is inside a sectoral system at various levels. The policy maker intervenes actively in the creation of knowledge, IPR, corporate governance rules, technology transfer, financial institutions, skill formation, public procurement. As a consequence, he or she has to develop competencies and an institutional setting in order to be effective and consistent at the various different levels.

\subsection{Policy should consider the different geographical dimensions of sectoral systems}

The sectoral approach takes into account the developments in the local, national, regional, and global levels of aggregation in markets and institutions. Developments at each of these levels influence the articulation of technological capabilities. While political boundaries and local proximity are influential in the generation and diffusion of innovation, modern enterprises in a liberalized global economy must take a global perspective on actual and potential competition. Policies that focus on only one level of aggregation are likely to miss constraints or opportunities that are influential in the innovative behaviour of individual organizations. While technology policies can and sometimes should be addressed at one level of aggregation, the rationale for these policies and their implementation must reflect a global perspective.

\subsection{Policies may play a key role in periods of radical technological change in sectoral systems}

A key issue may be the choice between supporting existing systems - 
with their historically accumulated knowledge bases - and supporting the development of new sectoral systems. Large-scale and radical technological shifts — i.e. shifts to new trajectories — have rarely taken place without public intervention in the OECD countries. This is true for most of electronics as well as for aircraft and biotechnology — also in the USA. In cases where technological change within a sector breaks from the past accumulation of knowledge and from current expertise and capability, sectoral systems of innovation will experience substantial stress because of the difficulties of aligning the incentives and the capabilities of the actors. For example, incumbent actors may underestimate the scope of change and focus on reactive rather than adaptive strategies. Adaptation in other parts of the sectoral system may therefore be delayed, increasing the long-term risks to the sector. Because sectoral systems are neither naturally given nor static and their boundaries, components and connections change significantly with the growth of knowledge and the evolution of problem sequences, a system can become outmoded and constrain innovation performance. Radical technological change often involves an especially pro-active role for public organizations in recognising and promoting or even creating the conditions for market success. Governments can play important roles as lead-users of radical new technologies and in supporting the early use of these technologies in public organizations. This is very clear in the case of public purchasing, in regard to defence capabilities and public health.

Three examples from ESSY research can be proposed. First, the innovation of the intraocular lens and the considerable changes over time in the related innovation system in the UK and USA depended greatly on the take up of the procedure in public and private health care systems, and on the different norms for translating clinical needs into 'market demand' in the two national medical systems. (Metcalfe \& James, 2001). Second, the US government has played a very active and decisive role in the launching of the fixed Internet (Corrocher, 2001). Finally, the Bioregio program in Germany is another interesting example.

In this respect, government capacities for monitoring the emergence of radical technological change differ substantially across countries. It is also particularly important to encourage transparent and open debates about the significance of emerging technologies to support the formation of consensus as well as to identify possibilities for experimentation and trial. 
If governments should intervene, they should intervene early in the development of new sub-systems and new sectoral systems of innovation. Such intervention at an early stage in the product/industry cycle may have a tremendous impact. In the case of the public creation of the NMT 450 mobile telecommunications technical standard in the Nordic countries about 20 years ago this proved to be important. It was crucial for the emergence of the mobile telephone industry and for the fact that both Ericsson and Nokia became global leaders in this field.

On a methodological level, a sectoral system approach indicates that existing approaches in industrial economics and standard measurement methods are not adequate to the task of identifying the changing configurations of sectoral systems and sub-systems of innovation, particularly the processes of knowledge exchange between different types of organizations. The costs of constructing new sectoral sub-systems of innovation are substantial but this activity is not explicitly recognised in the existing literature of policy or management. There are major strategic opportunities available in discovering better ways to monitor, promote, and reduce the costs of reconfiguration or expansion of sectoral systems and sub-systems of innovation.

\subsection{Additional sector-specific policy conclusions}

The emphasis on the diversity of sectoral systems highlights different policy measures for different sectors. These policy implications are closely related to the problems faced by the various actors operating in the sectoral context and to the sectoral specificity of knowledge, boundaries, actors and networks. Specific examples can be found in Edquist, 1997.

\section{Conclusions}

These general messages offer important additions to the existing body of knowledge supporting evidence-based policy. They reflect a considerable shift of emphasis in the formulation of innovation policies, which are, of course, much broader than policies for science and technology. Traditional innovation policies have been formulated in providing public resources for R\&D and 
changing the incentives for firms to innovate. Tax breaks for R\&D, innovation subsidies and patents are typical examples of these policies. A sectoral system perspective does not deny the significance of this approach but recognises that the effects may run rapidly into diminishing returns. To offset this it is necessary that innovation opportunities be enhanced and that this will be achieved through connecting firms within a wider division of innovative labour. Improving the organization of an innovation system within a sector is an almost certain route to improving the complementary payoffs from public and private $\mathrm{R} \& \mathrm{D}$.

The sectoral perspective provides a tool for policy makers to comprehend the differences in innovation systems and for identifying the specific actors that should be influenced by policy. The quid pro quo, however, is that policy makers need to invest much more effort in understanding the idiosyncrasies of the specific sectors that they use to channel the influence of policy. An approach to innovation policy that is not sensitive to the important sectoral distinctions may not yield much payoff to the policymaker (Edquist, 1997). 


\section{Bibliography}

Andersen, B.; Metcalfe, J.S.; Tether, B.S., Distributed Innovation Systems and Instituted Economic Processes (Working Paper ESSY), 2001.

Arduini, R.; Cesaroni, F., Environmental Technologies in the European Chemical Industry, in LEM (Working Paper, 2001/09), Pisa, Itália: Scuola Superiore Sant’Anna, 2001.

Arora, A.; Gambardella, A.; Garcia-Fontes, W., Investment Flows of Large Chemical Companies", Barcelona, Espanha: University Pompeu Fabra, (mimeo) 1998.

Audretsch, D., Innovation and Industry Evolution, Cambridge: MIT Press, 1996.

Bain, J., Barriers to new competition, Cambridge: Harvard University Press, 1956.

Bottazzi, G.; Dosi, G.; Rocchetti, G., Modes of Knowledge Accumulation, Entry Regimes and Patterns of Industrial Evolution (Working Paper ESSY), 2001.

Breschi, S.; Lissoni, F., Geographical Boundaries of Sectoral Systems (Working Paper ESSY), 2001.

Callon, M., "The dynamics of techno-economic networks", in Coombs R.; Saviotti P.; Walsh V. (eds.), Technical change and company strategies, London: Academy Press, 1992.

Carlsson, B.; Stankiewitz, R., "On the nature, function and composition of technological systems" in Carlsson, B. (ed.), Technological systems and economic performance, Kluner, Dordrecht, 1995.

Casper, S.; Kettler, H., National Institutional Frameworks and the Hybridization of Entrepreneurial Business Models: The German and UK Biotechnology Sectors (Working Paper ESSY), 2001.

Soskice, D., Patterns of Innovation and Varieties of Capitalism: Explaining the Development of High-Technology Entrepreneurialism in Europe (Working Paper ESSY), 2001.

Cefis, E.; Ciccarelli, M.; Orsenigo, L., Firms' Growth in the Pharmaceutical Industry (Working Paper ESSY), 2001.

Cesaroni, F. et al., The Chemical Sectoral System. Firms, markets, institutions and the processes of knowledge creation and diffusion (Working Paper ESSY), 2001.

Christensen, C.; Rosenbloom, R., "Explaining the Attacker Advantage", in Research Policy, 1995.

Cohen, W.; Levinthal, D., "Innovation and learning: the two faces of R\&D”, in Economic Journal, 99, p.569-596, 1989.

Cooke, P.; Gomez Urange, M.; Extebarria, Regional Innovation Systems: Institutional and Organizational dimensions, in Research Policy n. 4-5, p.475-493, 1997. 
Coriat, B.; Dosi, G., Learning how to govern and learning how to solve problems IIASA, Wien, 1994.

; Weinstein, O., Organizations and Institutions in the innovation generation, CREI Paris, 1999.

The Organization of R\&D and the Dynamics of Innovation A "Sectoral" View (Working Paper ESSY), 2001.

Corrocher, N., The Internet Services Industry: Sectoral Dynamics of Innovation and Production and Country-specific Trends in Italy and in the UK(Working Paper ESSY), 2001.

; Malerba, F., A literature review on the emergence of new technologies and new sectors (Working paper TENIA The emergence of new industrial activities), 2002.

Cowan, R., "Nuclear power reactors a study in technological lock", in Economic Journal, 1990.

; David, P.; Foray, D., "The explicit economics of knowledge codification and tacitness", in Industrial and Corporate Change, 2000.

D'Adderio, L., Inside the Virtual Product: the Influence of Integrated Software Systems on Organisational Knowledge Dynamics, SPRU, Brighton, University of Sussex, 2001.

The Diffusion of Integrated Software Solutions: Trends and Challenges (Working Paper ESSY), 2001.

Dahmen, E., "Development blocks in industrial economics", in Carlsson, B., Industrial dynamics, Kluwer, 1989.

Dalum, B., Data communication — the satellite and tv subsystems (Working Paper ESSY), 2001.

; Villumsen, G., Fixed Data Communications - Challenges For Europe (Working Paper ESSY), 2001.

Devetag, G., "From utilities to metal models: a critical survey on decision rules and cognition in consumer choice", in Industrial and Corporate Change, v.8, n.2 p.289-353, 1999.

Dosi, G., "Opportunities, incentives and the collective patterns of technological change", in Economic Journal, 1997.

"Sources, procedures and microeconomic effects of innovation", in Journal of Economic Literature, v.26, p.120-1171, 1998.

; Malerba F., Organization and strategy in the Evolution of the Enterprise, London: Mac Millan, 1996.

; Marengo L.; Fagiolo G., Learning evolutionary environments, IIASA Working Papers, 1998. 
Dubocage, E., The Financing of Innovation by Venture Capital in Europe and in the USA: a Comparative and Sectoral Approach (Working Paper ESSY), 2001.

Edquist, C., Systems of Innovation, London: Pinter Publishers, 1997.

; Johnson, B., "Institutions and organizations in systems of innovation", in Edquist C. (ed.), Systems of Innovation, London: Pinter Publishers, 1997.

Foray, D.; Grubler, A., "Morphological analysis, diffusion and lock-out of technologies: ferrous casting in France and the FRG", in Research Policy, 19, p. 535-550, 1990.

Foreman-Peck, J., "Technological lock-in and the power source for the motor car, University of Oxford", in Discussion Paper in Economics, 1996.

Freeman, C., The economics of industrial innovation, London: Pinter Publishers, 1982. Technology policy and economic performance: lessons from Japan, London: Pinter Publishers, 1987.

Friedman, A. L.; Cornford, D. S., Computer systems development - History, Organization and Implementation, Chichester: John Wiley and Sons, 1989.

Gambardella, A., Science and innovation in the US pharmaceutical industry, Cambridge: Cambridge University Press, 1995.

Geoffron, P., Rubinstein, M., Sectoral Systems of Innovation and Production (Working Paper ESSY), 2001.

Geroski, P., "What do we know about entry?”, in International Journal of Industrial Organization, 4, p.421-440, 1995.

, "Thinking creatively about markets", in International Journal of Industrial Organization, 16, 6, p.677-698, 1998.

Geuna, A.; Malo, S., Science-Technology Linkages in an Emerging Research Platform: The case of Combinatorial Chemistry and Biology, Scientometrics (forthcoming), 2000.

"The Evolution of Specialisation: Public Research in the Chemical and Pharmaceutical Industries", in SPRU, Brighton (UK): University of Sussex, (mimeo) 2000 .

Harvey, M.; Nyberg, A.; Metcalfe, J. S., Deep Transformation in The Service Economy: Innovation and Organizational Change in Food Retailing in Sweden and the UK (Working Paper ESSY), 2001.

Henderson, R.; Clark, K., "Architectural innovation”, in Administrative Science Quarterly, 35, p.9-30, 1990. 
; Orsenigo, L.; Pisano, G., "The pharmaceutical industry and the revolution in molecular biology" in Mowery, D.; Nelson R. (eds.), The Sources of Industrial Leadership, p.267-312, 1999 .

Hommen, L.; Manninen, E., GSM (Global System for Mobile Telecommunications) (Working Paper ESSY), 2001.

Howells, J., The Nature of Innovation in Services. Report presented to the OECD "Innovation and Productivity in Services Workshop", Sidney, Australia, 2000. (http://www.oecd.org/ dsti/sti/industry/indcomp).

Hughes, T. P., “The evolution of large technological systems”, in Bijker, W.; Hughes, T.; Pinch, T. (eds.), The social construction of technological systems, Cambridge: MIT Press, 1984.

Jovanovich, B.; McDonald, G. , “The life cycle of a competitive industry”, in Journal of Political Economy, v.162, n.2, p.322-347, 1994.

Klepper, S., "Entry, exit, growth and innovation over the product life cycle", in American Economic Review, 86, 562-583, 1996.

Koumpis, K.; Pavitt, K., "Corporate Activities in Speech Recognition and Natural Language: Another 'New-Science'-Based Technology", in International Journal of Innovation Management, vol.3 (3), p.335-366, 1999.

Lacetera, N., Corporate Governance and Innovation in the Pharmaceutical Industry: Some Further Evidence (Working Paper ESSY), 2001.

Lane, D., "Artificial Worlds an Economics", in Journal of Evolutionary Economics I, II, v.3, 1993.

Lehrer, M., From Factor of Production to Autonomous Industry: the Transformation of Germany's Software Sector (Working Paper ESSY), 2001.

Levin, R. et al., "Appropriating the returns from Industrial R\&D”, in Brookings Papers on Economic Activity, 3, p.783-831, 1987

Lundvall, B. A., National Systems of Innovation, London: Pinter Publishers, 1993.

; Johnson, B., “The learning economy”, in Journal of Industry Studies 1, 2, p.23-42, 1994.

Mahdi, S., Pavitt, K., "Key National Factors in the Emergence of Computational Chemistry Firms”, in International Journal of Innovation Management, v.1(4), p.355-386, 1997.

Malerba, F., "Learning by firms and incremental technical change", in Economic Journal, 102, p.845-59, 1992.

"Sectoral Systems of Innovation and Production", in Research Policy, 2002. 
; Orsenigo, L., "Schumpeterian patterns of innovation", in Journal of Economics, v.19. n.1, p.47-65, Cambridge, 1996.

,"Technological regimes and sectoral patterns of innovative activities", in Industrial and Corporate Change, v.6, p.83-117, 1997.

; __ "Technological entry, exit and survival: an empirical analysis of patent data”, in Research Policy, 28, p.643-660, 1999.

; "Knowledge, innovative activities and industry evolution", in Industrial and Corporate Change, 2000.

; Montobbio, F., Sectoral Systems, National Systems and International Technological and Trade Performance (Working Paper ESSY), 2001.

; Torrisi, S., "The dynamics of market structure and innovation in the Western European software industry", in Mowery, D. (ed.) The International Computer Software Industry: a Comparative Study of Industry Evolution and Structure, p.165-96, 1996.

Mansell, R.; Steinmueller, W. E., Mobilizing the Information Society, Oxford: Oxford University Press, 2000.

McKelvey, M., "Using evolutionary theory to define systems of innovation”, in Edquist, C. (ed.), Systems of Innovation: technologies, institutions and organizations, London: Pinter Publishers, 1997.

; Orsenigo L., Pharmaceuticals as a Sectoral Innovation System (Working Paper ESSY), 2001.

; Alm, H.; Riccaboni, M., Does Co-location matter? Knowledge Collaboration in the Swedish Biotechnology-Pharmaceutical Sector (Working Paper ESSY), 2001.

Meissner, G., SAP — Inside the Secret Software Power, New York: McGraw Hill, 2000.

Metcalfe, J. S.; James, A., Emergent Innovation Systems and the Delivery of Clinical Services: the Case of Intra-Ocular Lenses (Working Paper ESSY), 2001.

,Evolutionary economics and creative destruction, London: Routledge, 1998.

Montobbio, F., National Innovation Systems. A Critical Survey (Working Paper ESSY), 2001.

Mowery, D. (ed.), The international computer software industry: a comparative study of industry evolution and structure, Oxford: Oxford University Press, 1996.

; Nelson, R., The sources of industrial leadership, Cambridge: Cambridge University Press, 1999. 
Nelson, R., National Innovation Systems: a comparative study, Oxford: Oxford University Press, 1993.

, "The coevolution of technology, industrial structure and supporting institutions", in Industrial and Corporate Change, 1994.

, "Recent evolutionary theorizing about economic change", in Journal of Economic Literature, v.33, 1995.

; Rosenberg, N., "Technical innovation and national systems”, in Nelson, R. (ed.), in National Innovatin Systems, 1993.

; Sampat, B. N., Making sense of institutions as a factor shaping economic performance, (mimeo) 1998.

; Winter, S., An evolutionary theory of economic change, Cambridge: The Belknapp Press of Harvard University Press, 1982.

Orsenigo, L., The emergence of biotechnology London: Pinter Publishers, 1988.

Owen-Smith, J. et al., A Comparison of US and European University-Industry Relations in the Life Sciences (Working Paper ESSY), 2001.

Pavitt, K., "Sectoral patterns of technical change: towards a taxonomy and a theory, in Research Policy, 13, p.343-373, 1984.

Pollock, N.; Cornford, J., ERP systems and the university as a 'unique organisation'. Paper presented to the Critical Management Studies Conference, UMIST, Manchester, July 2001.

Rivaud-Danset, D., The Financing of Innovation and the Venture Capital, the National Financial and Sectoral Systems (Working Paper ESSY), 2001.

Saxenian, A., Regional Advantages, Cambridge: Harvard University Press, 1994.

Scherer, F. M., Industrial market structure and economic performance, Boston: Houghton Mifflin, 1990.

Steinmueller, W. E., Embedded Software: European Markets and Capabilities (Working Paper ESSY), 2001.

The Software Sectoral Innovation System: Open Source Software and the Alternatives (Working Paper ESSY), 2001.

Sutton, J., Sunk costs and market structure, Cambridge: MIT Press, 1991. , Technology and market structure, Cambridge: MIT Press, 1998. 
Teece, D.; Pisano, G., "The dynamic capabilities of firms: an introduction”, in Industrial and Corporate Change, v.3, 1994.

Tether, B. S.; Metcalfe, J. S.; Miles, I., Horndal at Heathrow? Co-operation, Learning and Innovation: Investigating the Processes of Runway Capacity Creation at Europe's most Congested Airports (Working Paper ESSY), 2001.
_ _ _ Innovation Systems \& Services. Investigating '_ Systems of Innovation' in the Services Sectors — an Overview (Working Paper ESSY), 2001.

Teubal, M.; Yinnon, T.; Zuscovitch, E., "Networks and market creation”, in Research Policy 20, p.381-392, 1991.

Tirole, J., The theory of industrial Organization, Cambridge: MIT Press, 1988.

Torrisi, S., Industrial organization and innovation: an international study of the software industry, Cheltenham: Edward Elgar, 1998.

Tushman, A., "Technological discontinuities and organizational environments", in Administrative Science Quarterly, 1986.

Utterback, J., Mastering the dynamics of innovation, Boston: Harvard Business School Press, 1994.

Von Hippel, E., The sources of Innovation, New York: Oxford University Press, 1988.

Wengel, J.; Shapira, P.; Machine Tools: The Remaking of a Traditional Sectoral Innovation System? (Working Paper ESSY) 2001.

Winter, G.; Kaniovski, Y. M.; Dosi, G., Modeling Industrial Dynamics with Innovative Entrants (Working Paper ESSY) 2001.

, "Schumpeterian competition in alternative technological regimes", in Journal of Economic Behaviour and Organization, 5, p.287-320, 1984. 